Tropical Journal of Pharmaceutical Research April 2021; 20 (4): 873-879

ISSN: $1596-5996$ (print); 1596-9827 (electronic)

(C) Pharmacotherapy Group, Faculty of Pharmacy, University of Benin, Benin City, 300001 Nigeria.

Original Research Article

http://dx.doi.org/10.4314/tjpr.v20i4.30

\title{
Effect of propofol and sevoflurane on perioperative and postoperative outcomes in lung cancer patients after thoracoscopic surgery
}

\author{
Ying Zhou, Ting $\mathbf{X u}$ * \\ Department of Anesthesiology, Ninth People's Hospital of Suzhou, Suzhou, Jiangsu 215200, China
}

*For correspondence: Email: 939777343@qq.com; Tel/Fax: 0086-0512-82881362

Sent for review: 8 October 2020

Revised accepted: 17 March 2021

\begin{abstract}
Purpose: To investigate the effects of propofol and sevoflurane on intraoperative and postoperative outcomes of lung cancer patients after thoracoscopic surgery.

Methods: Lung cancer patients $(n=265)$ aged $51-73$ years (mean age $=62 \pm 11$ years) who underwent thoracoscopic surgery under propofol or sevoflurane anesthesia were recruited over a 2-year period for this study. Data on perioperative pulmonary function, inflammatory responses, awakening time, postoperative pain and adverse reactions, pre- and postoperative cognitive functions, as well as duration of hospital stay were retrospectively analyzed.

Results: Perioperative pulmonary function was poor in patients who were operated under sevoflurane, relative to those who were operated under propofol $(p<0.05)$. After sternal closure (just before one-lung ventilation), levels of serum of interleukin 6 (IL-6), matrix metalloproteinase 9 (MMP-9), and S100 $\beta$ protein were reported to be higher in patients of sevoflurane group than those in propofol group, but interleukin 10 (IL-10) level was markedly reduced in sevoflurane group, relative to propofol group ( $p<$ 0.05). Awakening times and visual analog scale score of patients $24 \mathrm{~h}$ after thoracoscopic surgery of patients in sevoflurane group were significantly higher than those in propofol group $(p<0.05)$.

Conclusion: These results indicate that propofol is more effective than sevoflurane in the protection of pulmonary and cognitive functions of patients after thoracoscopic surgery. Thus, intravenous propofol anesthesia is recommended for thoracoscopic surgery for lung cancer.
\end{abstract}

Keywords: Cognitive function, Lung cancer, Propofol, Sevoflurane, Thoracoscopic surgery

\begin{abstract}
This is an Open Access article that uses a fund-ing model which does not charge readers or their institutions for access and distributed under the terms of the Creative Commons Attribution License (http://creativecommons.org/licenses/by/4.0) and the Budapest Open Access Initiative (http://www.budapestopenaccessinitiative.org/read), which permit unrestricted use, distribution, and reproduction in any medium, provided the original work is properly credited.
\end{abstract}

Tropical Journal of Pharmaceutical Research is indexed by Science Citation Index (SciSearch), Scopus, International Pharmaceutical Abstract, Chemical Abstracts, Embase, Index Copernicus, EBSCO, African Index Medicus, JournalSeek, Journal Citation Reports/Science Edition, Directory of Open Access Journals (DOAJ), African Journal Online, Bioline International, Open-J-Gate and Pharmacy Abstracts

\section{INTRODUCTION}

Lung cancer is a common malignant tumor among Chinese [1,2]. The disease is managed by thoracoscopic surgery and adjuvant therapies [3]. Lung cancer patients often miss timely treatment due to its insidious nature [4]. Thoracoscopic surgery causes trauma and triggers inflammatory response which adversely affects the living standard of patients after surgery. The surgical procedure also causes injury to other organs/tissues [5]. Proper use of narcotics is often advised during thoracoscopic surgery, since narcotic drugs inhibit the accumulation and release of neutrophils responsible for perioperative inflammation [6]. 
Propofol is a fast-acting drug with rapid action time, and low adverse actions. It is generally used in systematic anesthesia during thoracoscopic surgery [6]. Propofol has been reported to mitigate postoperative cognitive dysfunction [7]. Sevoflurane is an effective anesthetic in children and elderly patients [9]. Postoperative cognitive dysfunction (POCD) is a serious complication which accompanies major surgeries $[9,10]$. Studies on laparoscopic radical hysterectomy and lung cancer resection have demonstrated the effectiveness of propofol over sevoflurane in mitigating POCD [4,8,11]. Similarly, studies involving major cardiac surgeries and laparoscopic cholecystectomy have revealed the safety and effectiveness of sevoflurane in ameliorating POCD $[9,13,14]$. The actions of propofol and sevoflurane on intraoperative and post-surgical outcomes vary, but not much is known about their effect on cognitive function after thoracoscopic surgery [12].

This study investigated their actions on perioperative and postoperative outcomes in lung cancer patients after thoracoscopic surgery.

\section{METHODS}

\section{Materials}

Midazolam was product of Pfizer Inc. (USA), fentanyl was obtained from Taylor Pharmaceuticals (USA), and multifunctional monitor was bought from GE Healthcare (USA). Propofol was purchased from Fresenius Kabi AG (Germany). Sevoflurane was product of Abbott Healthcare Pvt. Ltd. (USA). Paracetamol was obtained from Bristol-Myers Squibb Pharmaceuticals Ltd (UK), while blood gas analyzer was obtained from Radiometer Medical Group (Denmark).

\section{General information on patients}

Lung cancer patients $(\mathrm{n}=265)$ aged $51-73$ years (mean age $=62 \pm 11$ years) who underwent thoracoscopic surgery under propofol or sevoflurane anesthesia at the Ninth People's Hospital of Suzhou, Suzhou, China were recruited over a 2-year period for this study. The inclusion criteria were: (1) patients diagnosed of lung cancer; (2) patients undergoing thoracoscopic surgery; and (3) patients who scored I or II in the American Society of Anesthesiologists (ASA) scoring system.

Patients with MMSE score $<24$ before induction of anesthesia were excluded from the study. The study protocol was approved by the Human Ethics Committee of the Ninth People's Hospital of Suzhou (approval no. NPHSCLPB111547) and carried out in adherence to the laws of China, the Helsinki Declaration (2008) [15] and Strengthening the Reporting of Observational Studies in Epidemiology (STROBE) [16]. Written informed consent was obtained from patients and their family members. Being a retrospective study, documentation in the Chinese clinical trial registry was waived by the institute.

\section{Study design}

The patients were assigned to 2 groups: propofol $(n=149)$ and sevoflurane $(n=116)$ groups. The operative patients received $0.1 \mathrm{mg}$ midazolam $/ \mathrm{kg}$ body weight (bwt) half an hour before induction of anesthesia, followed by intravenous injection of fentanyl (3 $\mu \mathrm{g} / \mathrm{kg}$ bwt). Physiological parameters of patients were monitored using multifunctional monitor. Patients in propofol group received $6 \mathrm{mg} / \mathrm{kg}$ bwt/h intravenous injection of propofol, while those in sevoflurane group were exposed to $8 \%$ sevoflurane via inhalation. After $5 \mathrm{~min}$ of ventilation, tracheal intubation was performed. Patients heart beat and blood pressure were maintained with anesthesia machine so as not to exceed $20 \%$ of baseline value. On completion of surgery, the patients received paracetamol infusion for 3 days (100 mL infusions/day). Pulmonary function and inflammatory response parameters were determined before induction of anesthesia, after sternal closure (just before one-lung ventilation), and $24 \mathrm{~h}$ after surgery.

\section{Determination of pulmonary function}

Arterial blood was drawn from patients and analyzed. Arterial blood gas was measured with a blood gas analyzer. Arterial/central line insertion procedure was performed during surgery where appropriate. Alveolar-arterial oxygen partial pressure difference (A-aDO2), respiratory index $(\mathrm{RI})$, and intra-pulmonary shunt fraction (Qs/Qt) were calculated from fraction of inspired oxygen $\left(\mathrm{FiO}_{2}\right)$, partial pressure of oxygen $\left(\mathrm{PaO}_{2}\right)$, that of carbon dioxide $\left(\mathrm{PaCO}_{2}\right)$, venous oxygen content $\left(\mathrm{CvO}_{2}\right)$, and arterial oxygen content $\left(\mathrm{CaO}_{2}\right)$ as shown in Eqs 1, 2 and 3 [17].

$$
\begin{aligned}
& A-a O_{2}=\left(F i O_{2}(713-5) / 4\left(\mathrm{PaCO}_{2}-\mathrm{PaO}_{2}\right)\right\} \ldots \text { (1) } \\
& R I=A-\left(a \mathrm{OO}_{2} / \mathrm{PaO}_{2}\right) \\
& Q s / Q t=\left\{\left(\mathrm{CcO}_{2}-\mathrm{CaO}_{2}\right) /\left(\mathrm{CcO}_{2}-\mathrm{CvO}_{2}\right)\right\}
\end{aligned}
$$




\section{Determination of levels of inflammatory mediators}

The protein levels of inflammatory mediators were determined in patients serum using their respective enzyme-linked immunosorbent assay (ELISA) kits [19].

\section{Assessment of cognitive function}

Mini-mental state examination (MMSE) was performed before induction of anesthesia, and 24 $\mathrm{h}$ after thoracoscopic surgery. A total of 11 questions covering a total of five areas of cognitive function (temporal orientation, spatial orientation, attention, calculation, recall, and language) were used for MMSE.

The highest score was 30, and scores < 24 were considered as indicative of cognitive impairment, while scores of 27 to 30 were considered normal. Scores of 21 to 26 were taken as indicative of mild condition of cognitive impairment. Scores ranging from 10 to 20 indicated moderate condition of cognitive impairment, while scores from $\leq 9$ indicated severe condition of cognitive impairment [10].

\section{Determination of awakening time}

Extubation time, eye-opening time, and response time of patients were recorded and analyzed at the end of thoracoscopic surgery. Extubation time was the time it took a patient to open his/her mouth for removal of endotracheal tube (ETT) at the end of anesthesia.

Eye-opening time was the time it took a patient to open his/her eye, while response time was the time taken to respond to external stimulus [4].

\section{Evaluation of postoperative pain}

Visual analog scale (VAS) was used to measure postoperative pain $24 \mathrm{~h}$ after thoracoscopic surgery (after patients regained consciousness). The score ranged from 0 to 10 (a score of 0 indicated no of pain, while a score 10 indicated maximum possible pain). Fentanyl injection (50 $\mu \mathrm{g} / \mathrm{kg}$ bwt) was intravenously administered in the event that VAS score was $\geq 3$.

\section{Measurement of adverse reactions}

Data on low blood pressure, bradycardia, nausea, and vomiting from the time when a patient was anesthetized to $24 \mathrm{~h}$ after thoracoscopic surgery were recorded and analyzed.

\section{Assessment of duration of hospital stay}

Duration of hospital stay was defined as the period from admission for thoracoscopic surgery to discharge.

\section{Statistical analysis}

Power analysis was performed using an online calculator, assuming $\alpha=0.05$ with a power $(\beta)$ of $80 \%$ and $95 \%$ confidence interval $(\mathrm{Cl})$. Qualitative data are expressed as relative frequency (percentage), while quantitative data are shown in the form of mean \pm standard deviation (SD). Qualitative data were compared using Student's $t$-test and quantitative data were compared using Fisher exact test. SPSS version 25.0 was used for statistical analysis. Values of $p$ $<0.05$ were considered significant.

\section{RESULTS}

\section{Perioperative profile of patients}

Significant differences were not reported for in clinical and demographic conditions, perioperative parameters, and surgical pathological characteristics between the two anesthesia groups before thoracoscopic surgery (Table 1).

\section{Effect of anesthesia on patients' pulmonary function}

Significant differences were not reported in AaDO2, RI, and Qs/Qt between the both groups of patients before the induction of anesthesia $(p>$ 0.05 for all). However, after sternal closure (just before one-lung ventilation), A-aDO2, RI, and Qs/Qt were significantly elevated in both groups, relative to the values before the induction of anesthesia ( $p<0.05$ for all). The values of these parameters $24 \mathrm{~h}$ after thoracoscopic surgery were not significantly different from those before induction of anesthesia $(p>0.05)$. Moreover, after sternal closure (just before one-lung ventilation), A-aDO2, RI, and Qs/Qt were reported higher in sevoflurane group as compared those in propofol group $(p<0.05$ for all).

\section{Effect of anesthesia on inflammatory responses of patients}

Before induction, there were no significant differences in the serum levels of inflammatory mediators in patients between the two groups ( $p$ $>0.05$ for all). 
Table 1: Clinical and demographic characteristics of patients (n, \%)

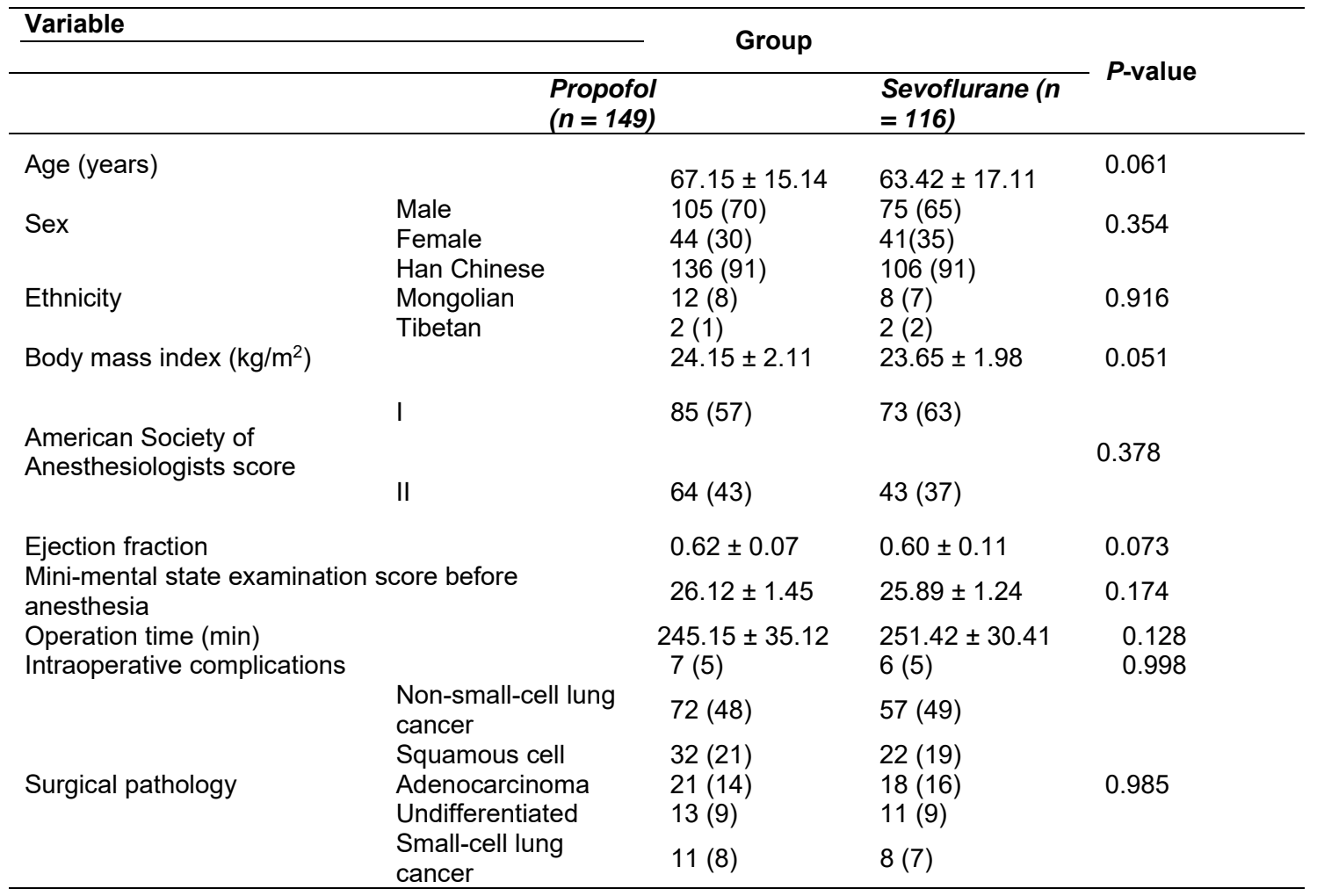

However, after induction of anesthesia, and $24 \mathrm{~h}$ after thoracoscopic surgery, serum levels of IL-6, MMP-9, and $S 100 \beta$ protein were increased in both groups, but serum level of IL-10 was decreased ( $p<0.05$ for all). Moreover, after sternal closure (just before one-lung ventilation), serum levels of IL-6, MMP-9, and $S 100 \beta$ were reported higher in sevoflurane group than in propofol group, but IL-10 level was markedly reduced in sevoflurane group, relative to propofol group $(p<0.05)$.

\section{Effect of anesthesia on awakening time}

As shown in Figure 1, extubation time, eyeopening time, and response time of patients in sevoflurane group were reported higher than those in propofol group $(p<0.05)$.

\section{Effect of anesthesia on postoperative pain}

Visual analog scale (VAS) score of patients in sevoflurane group $24 \mathrm{~h}$ after thoracoscopic surgery was reported higher than that of propofol group $(p<0.05)$. After surgery, patients in propofol group received lower amount of paracetamol infusion and fentanyl injection, relative to those in sevoflurane group $(p<0.05)$. However, at the time of discharge, significant difference was nor reported in postoperative pain of patients between the two groups $(p>0.05$; Table 2).

\section{Effect of anesthesia on the occurrence of adverse reactions}

There were fewer adverse reactions in the propofol group, relative to sevoflurane group $(p<$ 0.05 ). Low blood pressure and nausea occurred more frequently in sevoflurane group of patients than in propofol group, while patients in propofol group experienced bradycardia $(p<0.05$ for all; Table 3).

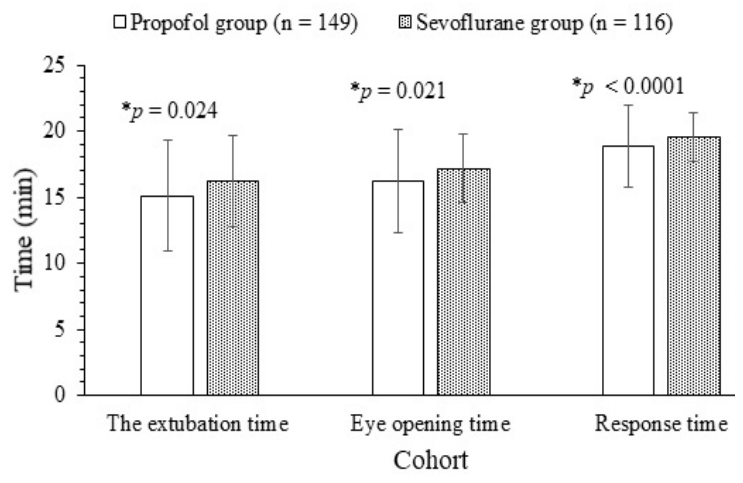

Figure 1: Comparison of awakening time after operation. ${ }^{*} p<0.05$ with respect to sevoflurane group 
Table 2: Comparison of VAS scores between the two groups ( $\mathrm{n}, \%)$

\begin{tabular}{lccl}
\hline $\begin{array}{l}\text { VAS } \\
\text { score }\end{array}$ & $\begin{array}{c}\text { Group } \\
\text { Propol }\end{array}$ & $\begin{array}{c}\text { Gevoflurane } \\
(\boldsymbol{n}=\mathbf{1 1 6})\end{array}$ & P-value \\
\hline 0 & $0(0)$ & $0(0)$ & \\
1 & $1(1)$ & $0(0)$ & \\
2 & $5(3)$ & $4(3)$ & \\
3 & $12(8)$ & $11(9)$ & \\
4 & $18(12)$ & $17(15)$ & \\
5 & $11(7)$ & $8(7)$ & \\
6 & $25(17)$ & $13(11)$ & $<0.0001$ \\
7 & $34(23)$ & $27(23)$ & \\
8 & $24(16)$ & $19(16)$ & \\
9 & $12(8)$ & $10(9)$ & \\
10 & $7(5)$ & $7(6)$ & \\
Mean \pm & $6.25 \pm$ & $6.27 \pm 2.16$ & \\
SD & 2.07 & & \\
\hline
\end{tabular}

Table 3: Adverse reactions of operative patients ( $\mathrm{n}$, $\%)$

\begin{tabular}{lccc}
\hline $\begin{array}{l}\text { Adverse } \\
\text { reaction }\end{array}$ & $\begin{array}{c}\text { Group } \\
\text { Propofol } \\
(\mathbf{n}=\mathbf{1 4 9})\end{array}$ & $\begin{array}{c}\text { Sevoflurane } \\
(\mathbf{n}=\mathbf{1 1 6})\end{array}$ & P-value \\
\cline { 1 - 2 } $\begin{array}{l}\text { Low blood } \\
\text { pressure }\end{array}$ & $5(3)$ & $11(9)^{*}$ & 0.014 \\
Bradycardia & $5(3)^{* *}$ & $1(1)$ & 0.045 \\
Nausea & $4(3)$ & $16(14)^{*}$ & 0.001 \\
Vomiting & $2(1)$ & $5(4)$ & 0.083 \\
$\begin{array}{l}\text { Total adverse } \\
\text { reactions }\end{array}$ & $16(11)$ & $33(28)$ & $<$ \\
\hline${ }^{*} P<0.05$, relative to propofol group; ${ }^{* *} p<0.05$, relative \\
to sevoflurane group
\end{tabular}

\section{Effect of anesthesia on cognitive function}

Mini-mental state examination (MMSE) score of patients in propofol group was reported higher than that in sevoflurane group $24 \mathrm{~h}$ after thoracoscopic surgery $(p<0.05)$. The MMSE values of both anesthesia groups were increased $24 \mathrm{~h}$ after thoracoscopic surgery, when compared to the values before induction of anesthesia $(p<0.05)$. In addition, $24 \mathrm{~h}$ after thoracoscopic surgery, 4 patients in propofol group and 11 patients in sevoflurane group developed mild condition of cognitive impairment. Moreover, there were no cases of moderate or severe cognitive impairment. The results are shown in Figure 2.

\section{Effect of anesthesia on duration of hospital stay}

Significant difference in the duration of stay in hospital was not reported between patients of the two anesthesia groups $(p>0.05)$.

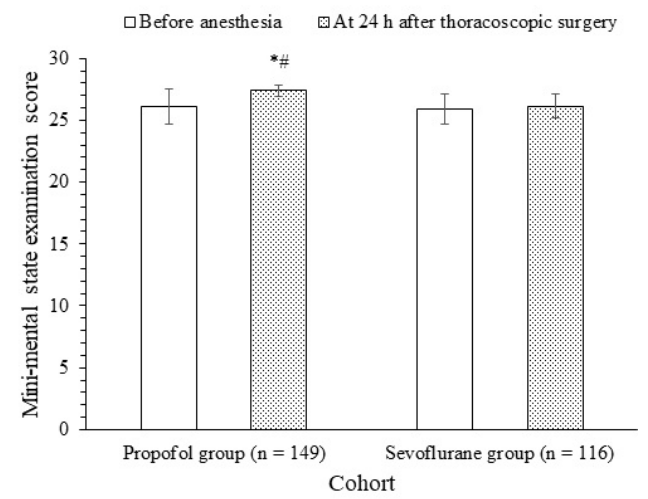

Figure 2: Comparison of MMSE scores. ${ }^{*} \mathrm{P}<0.05$, relative to sevoflurane group; ${ }^{*} p<0.05$, relative to value before induction of anesthesia

\section{DISCUSSION}

Postoperative cognitive dysfunction (POCD), a serious complication accompanying major surgeries in elderly patients, related to decline in memory and executive functions) and may last 1 year after surgery $[9,10]$.

Thoracoscopic surgery is a procedure used frequently to treat early-stage lung cancers. The actions of propofol and sevoflurane on perioperative and after operation outcomes differ, but little or nothing is known about their effects on cognitive function after thoracoscopic surgery [12]. Sevoflurane causes neurodegeneration characterized by aggregation of $\beta$-amyloid protein, changes in exploratory and anxiety-like behavior in patients, and activation of specific kinases that lead to phosphorylation of tau and spatial memory deficits. Propofol is a short-acting anesthetic drug. Propofol-induced hypnotic effect through GABA receptor. This study investigated the actions of propofol and sevoflurane on perioperative and after operation outcomes in lung cancer patients after thoracoscopic surgery.

The results revealed significantly poor perioperative pulmonary function in patients who received sevoflurane, relative to those who received propofol, and they are in agreement with reports in previous studies $[4,11,17]$. Thoracoscopic surgery impairs pulmonary function $[4,20,21]$. Sevoflurane causes lung edema and aggravates hypoxia via reduction in lung elasticity [17]. In this study, perioperative inflammatory response was markedly higher in sevoflurane group than in propofol group. These results are in agreement with reports in previous studies, and indicate that propofol may protect pulmonary function more effectively during thoracoscopic surgery than sevoflurane $[4,8,11,17]$. 
Thoracoscopic surgery has been reported to cause pulmonary edema [17]. It is likely that propofol inhibits inflammatory response during thoracoscopic surgery [25]. Studies have shown that sevoflurane significantly upregulated the expression of proinflammatory cytokines after inhalation [17]. In this study, awaking time, of patients in sevoflurane group were significantly higher than those in propofol group. There were fewer adverse reactions and markedly reduced postoperative pain in propofol group, relative to sevoflurane group. These results suggest that propofol may be relatively safer than sevoflurane during thoracoscopic surgery. This finding is in agreement with reports in a previous study [4].

The results obtained in this study showed that intravenous propofol markedly improved cognitive function in patients, and are consistent with findings in previous studies [11,12]. However, these results are not in agreement with those obtained in studies involving major cardiac surgeries and laparoscopic cholecystectomy [13]. The observed inconsistency may be due to differences in operational setting [12]. Thoracoscopic surgery decreases the ratio of ventilatory capacity to blood flow, which causes hypoxemia and postoperative cognitive impairments [26]. MMSE score is a simple, effective, and reliable method for evaluation of postoperative cognitive function [4]. The effectiveness of propofol over sevoflurane in the protection of cognitive function of patients after thoracoscopic surgery may be due to the fact that sevoflurane inhibits synaptic transmission for a longer period than propofol $[27,28]$.

\section{Limitations of the study}

The likely limitations of this study are: (1) small sample size/population; (2) short follow-up period; (3) failure to account for the influence of experience of surgeons on the occurrence of cognitive dysfunction in patients during surgery; (4) failure to perform multivariate analysis for an independent predictor of POCD; (5) failure to account for the possible effects of midazolam and fentanyl used during surgery on postoperative cognitive function; (6) failure to include other surgical parameters that could affect POCD; and (7) non-inclusion of a normal control group.

\section{CONCLUSION}

The results of this study indicate that propofol is more effective than sevoflurane in the protection of pulmonary and cognitive functions of patients after thoracoscopic surgery. Thus, intravenous propofol anesthesia is recommended for thoracoscopic surgery for lung cancer.

\section{DECLARATIONS}

\section{Acknowledgement}

The authors are thankful to the anesthesiologic, medical, pathological and nursing staff of The Ninth People's Hospital of Suzhou, Suzhou, China for support. No funding was received for this study.

\section{Conflict of interest}

No conflict of interest or any other competing interest is associated with this study.

\section{Contribution of authors}

We declare that this work was done by the authors named in this article and all liabilities pertaining to claims relating to the content of this article will be borne by the authors. The authors read and approved the manuscript for publication. Ying Zhou contributed to conceptualization, data curation, formal analysis, investigation, methodology of the study. Ting $\mathrm{Xu}$ contributed to project administration, resources, software, supervision, validation, visualization of the study, draft and edited the manuscript for intellectual content. The authors agree to be accountable for all aspects of work, including its integrity and accuracy.

\section{Availability of data and materials}

The datasets used and analyzed during the current study are available from the corresponding author on reasonable request.

\section{Open Access}

This is an Open Access article that uses a funding model which does not charge readers or their institutions for access and distributed under the terms of the Creative Commons Attribution License (http://creativecommons.org/licenses/by/ 4.0) and the Budapest Open Access Initiative (http://www.budapestopenaccessinitiative.org/rea d), which permit unrestricted use, distribution, and reproduction in any medium, provided the original work is properly credited.

\section{REFERENCES}

1. Xia M, Duan ML, Tong JH, Xu JG. MiR-26b suppresses tumor cell proliferation, migration and invasion by Trop J Pharm Res, April 2021; 20(4): 878 
directly targeting COX-2 in lung cancer. Eur Rev Med Pharmacol Sci 2015; 19(24): 4728-4737.

2. Kua LF, Ross S, Lee SC, Mimura K, Kono K, Goh BC, Yong WP. UGT1A6 polymorphisms modulated lung cancer risk in a Chinese population. PLoS One 2012; 7: 1-e42873-9-e42873.

3. Awad MM, Shaw AT. ALK inhibitors in non-small cell lung cancer: crizotinib and beyond. Clin Adv Hematol Oncol 2014; 12(7): 429-439.

4. Tian HT, Duan XH, Yang YF, Wang Y, Bai QL, Zhang X. Effects of propofol or sevoflurane anesthesia on the perioperative inflammatory response, pulmonary function and cognitive function in patients receiving lung cancer resection. Eur Rev Med Pharmacol Sci 2017; 21(23): 5515-5522.

5. Erturk K, Tastekin D, Bilgin E, Tas F, Disci R, Duranyildiz $D$. Clinical significance of serum protease activated receptor1 levels in patients with lung cancer. Eur Rev Med Pharmacol Sci 2016; 20(2): 243-249.

6. Chemali JJ, Van Dort CJ, Brown EN, Solt K. Active emergence from propofol general anesthesia is induced by methylphenidate. Anesthesiology 2012; 116(5): 9981005.

7. Cao YL, Zhang W, Ai YQ, Zhang WX, Li Y. Effect of propofol and ketamine anesthesia on cognitive function and immune function in young rats. Asian Pac J Trop Med 2014; 7(5): 407-411.

8. Peng X, Liu R, Zhu Y, Xu Q, Li J. Sevoflurane versus isoflurane for postoperative cognitive dysfunction of patients undergoing major cardiac surgeries: $A$ prospective cohort study. Indian J Pharm Educ 2019; 53(4): 710-715.

9. Chi YL, Li ZS, Lin CS, Wang Q, Zhou YK. Evaluation of the postoperative cognitive dysfunction in elderly patients with general anesthesia. Eur Rev Med Pharmacol Sci 2017; 21(6): 1346-1354.

10. Liu S, Gu X, Zhu L, Wu G, Zhou H, Song Y, Wu C. Effects of propofol and sevoflurane on perioperative immune response in patients undergoing laparoscopic radical hysterectomy for cervical cancer. Medicine 2016; 95(49): 1-e5479-6-e5479.

11. Wang G, Liu J, Gao J, Zheng X. Comparison of the effects of sevoflurane and propofol anesthesia on pulmonary function, MMP-9 and postoperative cognition in patients receiving lung cancer resection. Oncol Lett, 2019; 17(3): 3399-3405.

12. Goswami U, Babbar S, Tiwari S. Comparative evaluation of the effects of propofol and sevoflurane on cognitive function and memory in patients undergoing laparoscopic cholecystectomy: A randomised prospective study. Indian J Anaesth 2015; 59(3): 150 155.

13. Annecke T, Rehm M, Bruegger D, Kubitz JC, Kemming GI, Stoeckelhuber M, Becker BF, Conzen PF. Ischemiareperfusion-induced unmeasured anion generation and glycocalyx shedding: Sevoflurane versus propofol anesthesia. J Invest Surg 2012; 25(3): 162-168
14. Hou JF, Xiao CL. Effect of propofol and sevoflurane anesthesia on postoperative cognitive function and levels of $A \beta-42$ and $T a u$ in patients undergoing hepatectomy. Eur Rev Med Pharmacol Sci 2019; 23(2): 849-856.

15. Declaration of Helsinki (V2008). Available from: http://www.chictr.org.cn/uploads/documents/201610/df3 df4b49abd489e9eabf5d02e2bad45.pdf. [Access on 2 August 2020].

16. von Elm E, Altman DG, Egger M, Pocock SJ, Gotzsche $P C$, Vandenbroucke JP; STROBE Initiative. The Strengthening the Reporting of Observational Studies in Epidemiology (STROBE) Statement: Guidelines for reporting observational studies. Int J Surg 2014; 12(12): 1495-1499.

17. Zhiguo $Y$, Nanxiang Z, Jinyu M. Analysis of comparative anesthetic effects of sevoflurane and propofol on lung and cognitive functions. Pak J Pharm Sci 2019; 32(5(Special)): 2423-2426.

18. Piegeler T, Votta-Velis EG, Liu G, Place AT, Schwartz $D E$, Beck-Schimmer B, Minshall RD, Borgeat $A$. Antimetastatic potential of amide-linked local anesthetics: inhibition of lung adenocarcinoma cell migration and inflammatory Src signaling independent of sodium channel blockade. Anesthesiol 2012; 117(3): 548-559.

19. Hung MH, Chan KC, Liu YJ, Hsu HH, Chen KC, Cheng YJ, Chen JS. Non-intubated thoracoscopic lobectomy for lung cancer using epidural anesthesia and intercostal blockade: A retrospective cohort study of 238 cases. Medicine 2015; 94(13): 1-e727-8-e727.

20. Stiles BM, Poon A, Giambrone GP, Gaber-Baylis LK, Wu $X$, Lee PC, Port JL, Paul S, Bhat AU, Zabih R, et al. Incidence and factors associated with hospital readmission after pulmonary lobectomy. Ann Thorac Surg 2016; 101(2): 434-442.

21. Shi JG, Shao HJ, Jiang FE, Huang YD. Role of radiation therapy in lung cancer management -a review. Eur Rev Med Pharmacol Sci 2016; 20(5): 3217-3222.

22. Zhai HR, Yang $X N$, Nie $Q$, Liao $R Q$, Dong S, Li W, Jiang $B Y$, Yang JJ, Zhou Q, Tu HY, et al. Different dissecting orders of the pulmonary bronchus and vessels during right upper lobectomy are associated with surgical feasibility and postoperative recovery for lung cancer patients. Chin J Cancer 2017; 36(1): 53-1-53-10.

23. Charlesworth M, Ashworth A, Stirling S. Isoflurane use is not associated with prolonged intensive care unit stay following routine cardiac surgery when compared to sevoflurane. Can J Anaesth 2017; 64(1): 100-101.

24. Bellanti F, Mirabella L, Mitarotonda D, Blonda $M$, Tamborra R, Cinnella G, Fersini A, Ambrosi A, Dambrosio $M$, Vendemiale $G$, et al. Propofol but not sevoflurane prevents mitochondrial dysfunction and oxidative stress by limiting HIF-1a activation in hepatic ischemia/reperfusion injury. Free Radic Biol Med 2016; 96: 323-333. 